\title{
Testosterone does not adversely affect fibrinogen or tissue plasminogen activator (tPA) and plasminogen activator inhibitor-1 (PAI-1) levels in 46 men with chronic stable angina
}

\author{
A M Smith ${ }^{1,2}$, K M English ${ }^{2}$, C J Malkin ${ }^{2}$, R D Jones ${ }^{1}$, T H Jones ${ }^{1,3}$ and K S Channer ${ }^{2,4}$ \\ ${ }^{1}$ Hormone \& Vascular Biology Group, Academic Unit of Endocrinology, Division of Genomic Medicine, The University of Sheffield, Sheffield, S1O 2RX, \\ UK, ${ }^{2}$ Department of Cardiology, Royal Hallamshire Hospital, Sheffield Teaching Hospitals NHS Trust, Sheffield, S1O 2JF, UK, ${ }^{3}$ Center for Diabetes E \\ Endocrinology, Barnsley District General Hospital, Barnsley District Hospital NHS Trust, Barnsley, S57 5 RT, UK and ${ }^{4}$ Faculty of Health $\mathcal{E}$ Well-being, \\ Sheffield Hallam University, Collegiate Crescent, Sheffield, S1O 2BD, UK
}

(Correspondence should be addressed to K S Channer, Department of Cardiology, Royal Hallamshire Hospital, Glossop Road, Sheffield S1O 2JF, UK; Email: Kevin.Channer@sth.nhs.uk)

\begin{abstract}
Objective: In women, sex hormones cause increased morbidity and mortality in patients with coronary heart disease (CHD) and adversely affect the coagulation profile. We have studied the effect of physiological testosterone replacement therapy in men on coagulation factor expression, to determine if there is an increased risk of thrombosis.

Methods: Double-blind, randomized, placebo-controlled trial of testosterone in 46 men with chronic stable angina. Measurements of free, total and bioavailable testosterone, luteinising hormone (LH) and follicle-stimulating hormone (FSH), estradiol, plasminogen activator inhibitor-1 (PAI-1), fibrinogen, tissue plasminogen activator (tPA) and full blood count were made at 0, 6 and 14 weeks.

Results: Bioavailable testosterone levels were: $2.58 \pm 0.58 \mathrm{nmol} / \mathrm{l}$ at baseline, compared with $3.35 \pm 0.31 \mathrm{nmol} / \mathrm{l}$ at week $14(P<0.001)$ after treatment compared with $2.6 \pm 0.18 \mathrm{nmol} / \mathrm{l}$ and $2.44 \pm 0.18 \mathrm{nmol} / \mathrm{l}$ in the placebo group ( $P$ was not significant). There was no change in fibrinogen $(3.03 \pm 0.18 \mathrm{~g} / \mathrm{l}$ at baseline and $3.02 \pm 0.18 \mathrm{~g} / \mathrm{l}$ at week $14, P=0.24)$, tPA activity $(26.77 \pm 4.9 \mathrm{Iu} / \mathrm{ml}$ and $25.67 \pm 4.4 \mathrm{Iu} / \mathrm{ml}, \quad P=0.88)$ or PAI- 1 activity $(0.49 \pm 0.85 \mathrm{Iu} / \mathrm{ml}$ and $0.36 \pm 0.06 \mathrm{Iu} / \mathrm{ml}, P=0.16$ ) with active treatment and no differences between the groups (at week $14, P$ value $0.98,0.59$ and 0.8 for fibrinogen, PAI-1 and tPA respectively). Haemoglobin concentration did not change over time, in the testosterone group $(1.44 \pm 0.02 \mathrm{~g} / \mathrm{l}$ and $1.45 \pm 0.02 \mathrm{~g} / \mathrm{l}$, $P=0.22$ ).

Conclusion: Physiological testosterone replacement does not adversely affect blood coagulation status.
\end{abstract}

European Journal of Endocrinology 152 285-291

\section{Introduction}

Coronary heart disease (CHD) is the commonest cause of death in the UK, with 120000 people (approximately one in four men and one in six women) dying from CHD in 2001 (1). This gender-specific incidence is consistent between countries and is not due to differences in classical cardiovascular risk factors $(2,3)$. It has been postulated that the difference observed between the sexes may be due to a cardioprotective effect of endogenous female sex hormones, and that hormone replacement therapy (HRT) might be beneficial in postmenopausal women, thereby reducing the incidence of ischaemic heart disease. This hypothesis would appear to have been supported by observational studies that showed a reduced risk of CHD associated with HRT in women $(4,5)$. However, three recent large prospective randomized controlled trials of HRT have shown no significant decrease in the rates of primary or secondary cardiovascular events (6-8). There was however a highly significant increase in venous thromboembolism associated with the use of HRT.

Recently, the role the male sex hormone testosterone plays in CHD has received increasing attention. In men, levels of testosterone fall with increasing age $(9,10)$ and it is in the elderly population that the highest rates of $\mathrm{CHD}$ are found. Low plasma testosterone levels in men are associated with known risk factors for CHD including age, hypertension, obesity, raised fibrinogen, hyperinsulinaemia, diabetes mellitus and adverse lipid profile (11). Males with CHD have lower serum levels of bioavailable testosterone than men of a similar age with normal coronary angiograms (12). In symptomatic patients with angina a number of studies have demonstrated that testosterone treatment prolongs the time to myocardial ischaemia compared 
with placebo $(13-17)$. Testosterone treatment reduces diet-induced atherosclerosis in animal studies (18), and human studies have also investigated the relationship between the serum testosterone concentration and atherosclerosis. Two studies have demonstrated an inverse relationship between serum testosterone and the degree of atherosclerosis as determined by carotid artery intima-media thickness on ultrasound $(19,20)$. Serum testosterone levels were also inversely related in a further study (21), although the degree of atherosclerosis of the abdominal aorta was measured radiographically.

The majority of cases of myocardial infarction (MI) are caused by thrombotic coronary occlusion. The thrombotic process is complicated with various pro- and anti-thrombotic mediators determining the coagulation status. The major pro-thrombotic factors are plasminogen activator inhibitor-1 (PAI-1), fibrinogen, alpha-2-antiplasmin and factor VIIc, whilst tissue plasminogen activator (tPA), protein $\mathrm{C}$ and anti-thrombin III are important anti-thrombotic agents. It has been shown that PAI-1 is of particular importance in $\mathrm{CHD}$, with elevated levels predicting $\mathrm{MI}$ and progression of atherosclerosis in stable CHD patients $(22,23)$. Crosssectional studies have reported a positive association between testosterone levels and tPA and a negative association with PAI-1, VIIc and fibrinogen $(14,15,24)$. Replacement of testosterone in hypogonadal men and treatment of normal men with dehydroepiandrosterone (DHEA) reduces PAI-1 serum levels, whilst testosterone administration in healthy men also reduces plasma levels of the acute phase protein fibrinogen (23), which is an independent risk factor for CAD (25).

In this study we have evaluated the role of 3 months of physiological testosterone therapy upon fibrinogen, PAI-1 and tPA activity levels in men with chronic stable angina.

\section{Subjects and methods}

\section{Methods}

This was a double-blind, randomized, placebo-controlled, add-on trial. Subjects entered an initial 2-week, single-blind, placebo run-in period, followed by doubleblind randomization to active or placebo treatment for 12 weeks. Subjects applied two $2.5 \mathrm{mg}$ self-adhesive active testosterone or placebo patches each night before retiring. The main results have previously been reported (26). Measurements of free, total and bioavailable testosterone and PAI-1 activity, fibrinogen and tPA activity were undertaken at week 0,6 and 14 .

\section{Subjects}

Sixty one men with CHD ( $>70 \%$ stenosis of a major coronary artery at coronary angiography, previous proven
MI, or typical symptoms of angina pectoris and a 'double positive' (>1 mm downsloping ST-segment (the segment between the $\mathrm{S}$ and the $\mathrm{T}$ wave on the ECG) depression associated with chest pain) treadmill exercise test) were recruited. All patients gave written informed consent, and the study was approved by the local ethics committee. No changes were made to antianginal medication for 4 weeks before or during the trial. Patients were excluded if they had a prostate specific antigen (PSA) level above the normal range or any other contraindication to testosterone therapy. Subjects with severe hypertension (blood pressure $>180 / 114$ $\mathrm{mmHg}$ ), significant arrhythmias or who had left main stem (or equivalent) stenosis, a coronary or cerebrovascular event, or had taken other trial drugs in the last 3 months were also excluded.

Of the 61 patients screened, 53 entered the singleblind placebo run-in phase. Of these 53, 50 patients completed the single-blind run-in phase. Twenty-five patients were randomized to each group. Three patients were withdrawn from the active treatment arm: one suffered a MI, one had severe skin irritation, and one had an elective coronary angioplasty performed earlier than expected. One patient withdrew from the placebo arm complaining of depression. All early withdrawals after the placebo run-in occurred before the first assessment of double-blind treatment; therefore, these subjects were excluded from the final analysis. Twenty-two patients completed active treatment and 24 completed placebo treatment; all included in the final analysis (Table 1).

\section{Trial drug}

Testosterone was given via a transdermal patch delivery system (Andropatch, GlaxoSmithKline). Identical placebo patches were manufactured by Thera-Tech Inc. (Bloomingdale, IL, USA) Subjects applied two $2.5 \mathrm{mg}$ patches at night, a dose that has previously been shown to raise levels of testosterone to within the normal range in 93\% of hypogonadal men and to mimic the normal diurnal variation in hormone levels seen in vivo (27).

\section{Patient assessment}

Patients were assessed at week 0, 6 and 14 and measurements were made of free, total and bioavailable testosterone, sex hormone binding globulin (SHBG), estradiol, lutenising hormone (LH), follicle-stimulating hormone (FSH), full blood count and the fibrinolytic markers, fibrinogen, tPA activity and PAI-1 activity. PSA was measured at the beginning and end of the trial. A medical history was taken, documenting risk factors for $\mathrm{CAD}$ and drug history. Baseline recordings were also taken of body mass index, waist to hip ratio, systolic $\mathrm{BP}$, diastolic $\mathrm{BP}$, cardiac output and pulse. 
Table 1 Baseline characteristics of 46 men with CHD before testosterone (active) or placebo treatment. Values are means \pm S.E.M. unless otherwise stated.

\begin{tabular}{|c|c|c|}
\hline $\begin{array}{l}\text { Baseline } \\
\text { characteristics }\end{array}$ & $\begin{array}{l}\text { Active treatment } \\
\qquad(n=22)\end{array}$ & $\begin{array}{l}\text { Placebo treatment } \\
\quad(n=24)\end{array}$ \\
\hline Age, years & $62 \pm 2$ & $62 \pm 2$ \\
\hline \multicolumn{3}{|l|}{$\begin{array}{l}\text { Diagnosis of CAD, } \\
n(\%)\end{array}$} \\
\hline Angiogram & $14(64)$ & $18(75)$ \\
\hline Previous MI & $3(14)$ & $2(8)$ \\
\hline Angina + ETT & $5(22)$ & $4(17)$ \\
\hline \multicolumn{3}{|l|}{ Risk Factors, $n(\%)$} \\
\hline Hypertension & $4(18)$ & $14(58)^{\star}$ \\
\hline Diabetes mellitus & $2(9)$ & $5(21)$ \\
\hline Family history & $8(36)$ & $13(54)$ \\
\hline Current smoker & $1(4)$ & 4 (16) \\
\hline $\begin{array}{l}\text { Hypercholesterolaemia } \\
\text { at presentation }\end{array}$ & $15(68)$ & $18(75)$ \\
\hline \multicolumn{3}{|l|}{$\begin{array}{l}\text { Concurrent medication, } \\
n(\%)\end{array}$} \\
\hline NSAID (Aspirin) & $22(100)$ & $24(100)$ \\
\hline B-blocker & $18(81)$ & $20(83)$ \\
\hline Long-acting nitrate & $11(50)$ & $11(45)$ \\
\hline Calcium channel blocker & $11(50)$ & $12(50)$ \\
\hline $\begin{array}{l}\text { Potassium channel } \\
\text { opener }\end{array}$ & $1(4)$ & $3(12)$ \\
\hline Statin & $13(59)$ & $17(70)$ \\
\hline ACE-I & $3(13)$ & $5(20)$ \\
\hline Diuretics & $2(9)^{\prime}$ & $9(37)^{\star \star}$ \\
\hline \multicolumn{3}{|l|}{ Baseline recordings } \\
\hline $\begin{array}{l}\text { Body mass index, } \\
\mathrm{kg} / \mathrm{m}^{2}\end{array}$ & $27.7 \pm 0.7$ & $28.4 \pm 0.8$ \\
\hline Waist-to-hip ratio & $0.96 \pm 0.1$ & $0.98 \pm 0.01$ \\
\hline Systolic BP, mmHg & $131 \pm 4$ & $142 \pm 4^{\star \star \star}$ \\
\hline Diastolic BP, mmHg & $78 \pm 2$ & $80 \pm 2.3$ \\
\hline Cardiac output, I/min & $3.8 \pm 0.2$ & $3.7 \pm 0.3$ \\
\hline Pulse, bpm & $61 \pm 3$ & $63 \pm 2$ \\
\hline
\end{tabular}

CAD, coronary heart disease; MI, myocardial infarction; ETT, exercise treadmill testing; ACE-I, angiotensin converting enzyme-inhibitor; BP, blood pressure.

${ }^{\star} \lambda 2=7.8, P<0.01 ;{ }^{\star \star} \lambda 2=5.1, P<0.05 ;{ }^{* \star} P<0.05$.

\section{Laboratory measurements}

Serum-total and -free testosterone were measured using radio-immuno-assay (Coat-A-Count, Diagnostic Products Corporation, Tyne and Wear, UK), with inter-assay coefficient of variation $5.5 \%$ at $16.3 \mathrm{pmol} / \mathrm{l}, 3.4 \%$ at $147 \mathrm{pmol} / \mathrm{l}, 11.2 \%$ at $3.6 \mathrm{nmol} / \mathrm{l}$ and $6.1 \%$ at $13.1 \mathrm{nmol} / \mathrm{l}$. Percentage bioavailable testosterone was assayed using an adaptation of the methods described by Tremblay \& Dube (24), where $3 \mathrm{H}$-labelled testosterone radioactive tracer was measured in the supernatant fraction following ammonium sulphate precipitation of sex hormone binding globulin. The concentration of bioavailable testosterone was then calculated from the percentage of the total steroid. Inter-assay variation was less than $8 \%$ throughout the range of the assay. Estradiol was measured by an automated competitive enzyme-immuno-assay (Immulite, Diagnostic Products Corporation, Los Angeles, USA), with inter-assay coefficient of variation $16.7 \%$ at $242 \mathrm{pmol} / \mathrm{l}, 9.1 \%$ at $2420 \mathrm{pmol} / \mathrm{l}$ and $10 \%$ at $5381 \mathrm{pmol} / \mathrm{l}$. LH and FSH were measured using an automated micro-particleimmuno-assay (Abbott Axsym). Inter-assay coefficient of variation was $8.0 \%$ at $4.5 \mathrm{Iu} / \mathrm{l}, 6.3 \%$ at $17.1 \mathrm{Iu} / \mathrm{l}$, $12.0 \%$ at $41.7 \mathrm{Iu} / \mathrm{l}$ and $6.3 \%$ at $8.9 \mathrm{Iu} / \mathrm{l}, 7.7 \%$ at $19.4 \mathrm{Iu} / \mathrm{l}$ and $6.8 \%$ at $41.7 \mathrm{Iu} / \mathrm{l}$. Fibrinogen levels were analyzed using a method modified from the Von Clauss assay. The fibrinogen concentration affects the time taken for fibrin formation after dade thrombin is added to dilute plasma. The time taken for clot formation to occur was measured on the Clauss CA6000 machine, this was then converted to a fibrinogen concentration using a calibration curve. Interassay coefficient of variation was $<9 \%$. Measurement of the activity levels of tPA and PAI-1 involved taking blood samples into Stabilyte tubes that were placed immediately on ice to reduce the blood $\mathrm{pH}$ to 5.9. This inhibited PAI-1/tPA complex formation, thereby preserving blood levels. Levels were using the Biopool Chromolize bio-functional immunosorbent assay (Biopool International, Venova, USA/Umea, Sweden). Inter-assay coefficients of variation for tPA were $5.2 \%$ at mid range and $5.3 \%$ at the lower range of the assay and for PAI-1 they were $16.9 \%$ at $2 \mathrm{Iu} / \mathrm{ml}$, $4.6 \%$ at $22 \mathrm{Iu} / \mathrm{ml}$ and 3.6 at $36 \mathrm{Iu} / \mathrm{ml}$. Haemoglobin concentration was measured using the fully automated Coulter STKS system.

\section{Statistical analysis}

We confirmed the data were parametric using Kolmogorov-Smirnov test. In subsequent analysis, unpaired, paired Student's $t$-test or ANCOVA was used as appropriate. For analysis of differences over time, time point and group were entered as fixed factors and baseline values as a covariate to adjust for slight differences in baseline values. Unless otherwise stated data are expressed as means \pm S.E.M. Statistical significance was accepted at $P<0.05$.

\section{Results}

\section{Safety data}

The transdermal testosterone delivery system was well tolerated, with the main side effect being skin irritation. Eleven patients reported this on active treatment and six on placebo. One patient, who was awaiting coronary revascularization, suffered a myocardial infarction whilst on active treatment. There was no significant change in PSA in either group.

\section{Patient demographics}

Patients in the active and placebo-treated groups were well matched, with similar ages and proportions in the diagnosis of CAD. However the placebo group had a higher incidence of risk factors for $\mathrm{CAD}$, higher systolic blood pressure and higher diuretic use (Table 1). 


\section{Hormone levels}

The hormone levels at baseline and weeks 6 and 14 are shown in Table 2. At baseline, the mean testosterone levels were at the lower limit of normal in both groups (bioavailable testosterone $=2.58 \pm 0.28 \mathrm{nmol} / \mathrm{l}$ in the active group compared with $2.60 \pm 0.18 \mathrm{nmol} / \mathrm{l}$ in the placebo group, normal range $>2.5 \mathrm{nmol} / \mathrm{l}$ ). Active treatment led to a significant increase in the level of testosterone, which peaked at week 6 and waned slightly by week 14 (Table 2). These changes were reflected in changes in the levels of gonadotrophins (Table 2). There were no significant changes in any serum measurements in the placebo group (Table 2).

\section{Fibrinogen, tPA and PAI-1 levels}

The coagulation marker levels are shown at baseline and week 6 and 14 in Table 3. There was no change in the levels of fibrinogen, tPA activity or PAI-1 activity over time, with no differences between the testosterone and placebo-treated groups (Table 3).

\section{Discussion}

In this study we have shown that administration of physiological doses of supplemental testosterone to men with chronic stable angina does not adversely affect the coagulation system, indeed no significant changes were found in the levels of tPA and PAI-1 activities or fibrinogen level. This is the first study to assess the influence of physiological doses of testosterone upon haemostatic factors in men with CHD.

Previous studies have suggested that testosterone may be associated with a beneficial effect upon coagulation. Philips et al. (28) studied the association between testosterone levels and fibrinolytic factors in men undergoing angiography for chest pain or an abnormal exercise treadmill test, but excluding patients with previous MI. An estimate of the degree of CAD was taken from the angiogram and this was compared with hormone and fibrinolytic marker levels. Results showed that the testosterone level was correlated negatively with CAD and PAI-1 (28). A subgroup analysis showed a negative association with fibrinogen when patients with hypertension, diabetes or major medical disorders were excluded (28). Another study investigated the relationship between testosterone levels, fibrinolytic activity and lipid levels, in hyperlipidaemic men (29). It was reported that testosterone was positively associated with tPA activity and inversely associated with PAI-1 activity and fibrinogen levels (29). Similarly a potentially beneficial effect of testosterone upon coagulation was reported in men in the period after an acute MI (30). Both total and bioavailable testosterone fell transiently in the first $24 \mathrm{~h}$ post-infarction. In contrast, following thrombolysis there was a rise in

Table 2 Levels of total, free and total testosterone, LH, FSH and Estradiol in male CHD patients, at different time points, during testosterone (active) or placebo treatment. Values are means \pm S.E.M. unless otherwise stated.

\begin{tabular}{|c|c|c|c|c|}
\hline & Baseline & Week 6 & Week 14 & $P$ value \\
\hline \multicolumn{5}{|c|}{ Total testosterone (RR 7.5-37.0), nmol/l } \\
\hline Active & $13.55 \pm 0.78$ & $22.34 \pm 1.19$ & $18.57 \pm 1.6$ & \multirow[t]{3}{*}{$<0.0001$} \\
\hline Placebo & $12.38 \pm 0.72$ & $11.35 \pm 0.76$ & $12.23 \pm 0.89$ & \\
\hline$P$ & 0.3 & $<0.001^{*}$ & $<0.001^{*}$ & \\
\hline \multicolumn{5}{|c|}{ Free testosterone (RR 37.4-138.7), pmol// } \\
\hline Active & $45.68 \pm 2.42$ & $84.70 \pm 4.89$ & $72.56 \pm 5.8$ & \multirow[t]{3}{*}{$<0.0001$} \\
\hline Placebo & $46.36 \pm 2.54$ & $44.86 \pm 2.76$ & $48.69 \pm 3.29$ & \\
\hline$P$ & 0.9 & $<0.0001^{\star}$ & $<0.001^{*}$ & \\
\hline \multicolumn{5}{|c|}{ Bioavailable testosterone $(\mathrm{RR}>2.5), \mathrm{nmol} / \mathrm{l}$} \\
\hline Active & $2.58 \pm 0.28$ & $4.34 \pm 0.26$ & $3.35 \pm 0.31$ & \multirow[t]{3}{*}{$<0.001$} \\
\hline Placebo & $2.6 \pm 0.18$ & $2.42 \pm 0.22$ & $2.44 \pm 0.18$ & \\
\hline$P$ & 0.5 & $<0.0001^{*}$ & $0.01^{*}$ & \\
\hline \multicolumn{5}{|c|}{ LH (RR 1.3-9.1), IU/I } \\
\hline Active & $4.49 \pm 0.61$ & $1.95 \pm 0.35$ & $2.72 \pm 0.67$ & \multirow[t]{3}{*}{$<0.0001$} \\
\hline Placebo & $5.28 \pm 0.58$ & $5.46 \pm 0.61$ & $5.15 \pm 0.55$ & \\
\hline$P$ & 0.358 & $<0.0001^{*}$ & $<0.005^{\star}$ & \\
\hline \multicolumn{5}{|c|}{ FSH (RR 1.7-12.6), IU/I } \\
\hline Active & $6.43 \pm 0.91$ & $3.22 \pm 0.59$ & $3.29 \pm 0.74$ & \multirow[t]{3}{*}{$<0.0001$} \\
\hline Placebo & $6.88 \pm 0.91$ & $6.98 \pm 0.91$ & $7.0 \pm 0.88$ & \\
\hline$P$ & 0.7 & $0.001^{*}$ & $<0.005^{\star}$ & \\
\hline \multicolumn{5}{|c|}{ Estradiol $(\mathrm{RR}<150), \mathrm{pmol} / \mathrm{l}$} \\
\hline Active & $70.27 \pm 6.05$ & $80.50 \pm 6.6$ & $77.68 \pm 4.8$ & \multirow[t]{3}{*}{0.301} \\
\hline Placebo & $67.75 \pm 4.0$ & $72.13 \pm 4.2$ & $76.46 \pm 3.8$ & \\
\hline$P$ & 0.7 & 0.3 & 0.8 & \\
\hline
\end{tabular}

RR; reference range; $\mathrm{LH}$, luteinising hormone; FSH, follicle-stimulating hormone. Probability values across the groups calculated with ANCOVA; between the 2 groups, with Student's $t$-test for independent variables. ${ }^{*}$ Statistically significant; $P<0.05$. 
Table 3 Levels of fibrinogen, PAI-1, tPA and haemoglobin in male $\mathrm{CHD}$ patients, at different time points, during testosterone (active) or placebo treatment. Values are means \pm S.E.M. unless otherwise stated.

\begin{tabular}{lcccc}
\hline & Baseline & Week 6 & Week 14 & $\boldsymbol{P}$ \\
\hline Fibrinogen, g/l & & & & \\
Active & $3.03 \pm 0.18$ & $3.0 \pm 0.19$ & $3.02 \pm 0.18$ & 0.24 \\
Placebo & $3.37 \pm 0.17$ & $3.36 \pm 0.21$ & $3.02 \pm 0.19$ & \\
$P$ & 0.19 & 0.22 & 0.98 & \\
PAl-1, lu/ml & & & & \\
Active & $26.77 \pm 4.9$ & $28.80 \pm 4.84$ & $25.67 \pm 4.38$ & 0.16 \\
Placebo & $29.13 \pm 3.57$ & $35.27 \pm 5.20$ & $28.99 \pm 4.25$ & \\
$P$ & 0.7 & 0.37 & 0.59 & \\
tPA, lu/ml & & & & \\
Active & $0.49 \pm 0.85$ & $0.39 \pm 0.11$ & $0.36 \pm 0.06$ & 0.88 \\
Placebo & $0.42 \pm 0.86$ & $0.32 \pm 0.68$ & $0.33 \pm 0.07$ & \\
$P$ & 0.6 & 0.59 & 0.8 & \\
Haemoglobin, g/l & & & & \\
Active & $1.44 \pm 0.02$ & $1.43 \pm 0.02$ & $1.45 \pm 0.02$ & 0.22 \\
Placebo & $1.47 \pm 0.02$ & $1.44 \pm 0.02$ & $1.45 \pm 0.02$ & \\
$P$ & 0.82 & 0.89 & 0.83 & \\
\hline
\end{tabular}

PAl-1, Plasminogen activator inhibitor-1; tPA, tissue plasminogen activator Probability values across the groups calculated with ANCOVA; between the 2 groups, with Student's $t$-test for independent variables.

PAI-1 activity, which could lead to a relatively prothrombotic state (30). The greater the fall in testosterone following MI, the higher PAI-1 activity and lower tPA activity (30), suggesting a similar interaction between testosterone, PAI-1 and tPA. In addition, the anti-thrombotic influence of testosterone maybe potentially lost following an MI (30).

Supraphysiological testosterone therapy is also reported to modulate coagulation factor expression. In a study of 32 healthy men who received $200 \mathrm{mg}$ testosterone oethanthate by weekly intramuscular injection for 52 weeks in a trial of hormonal male contraception (31), testosterone therapy resulted in a reduction in fibrinogen and PAI-1activity, together with decreases in serum concentrations of the prothrombotic factors protein $\mathrm{C}$ and protein S (31). There was no change in the level of tPA, although an increase in antithrombin III activity was observed (31). Apart from fibrinogen, the observed alterations in haemostatic factors returned to pretreatment levels during continued treatment. An increase in both haemoglobin and haematocrit was noticed which was sustained throughout the study period (31). It was concluded that supraphysiological doses of testosterone do not result in a pro-thrombotic state, which is supported by our current study. The lack of effect upon fibrinogen and PAI-1 activity in the current study is likely to be a consequence of the smaller, physiological doses of testosterone that were used, but these more accurately reflect serum levels generated by testosterone replacement.

These studies have investigated the potential antithrombotic role of testosterone and the relationship with $\mathrm{CHD}$. HRT has previously been hypothesized to reduce the incidence of $\mathrm{CHD}$ in postmenopausal women. However the Heart and Estrogen/Progestin Replacement study (HERS) (6) reported an increase in vascular events and death in the first year of treatment, which has been postulated to be due to the increased risk of arterial thrombosis leading to MI or stroke. One theory used to explain the unexpected increased vascular risk was that the HRT preparation used in these trials combined estrogens and progesterones, with the latter confounding any potential benefit of the former. However, this was later disproved in the ESPRIT trial (32), in which women who had had their first MI where randomized to either estradiol or placebo, no beneficial effect in the risk of secondary cardiovascular events was found. The risk of venous thromboembolism is also increased with female HRT. The Women's Health Initiative (WHI) trial (7) reported a two-fold increase in vascular events and death, with marked similarity to the results of HERS/HERS II $(6,8)$.The risk was highest in the period immediately after commencing HRT and this is thought to be due to an enhancement of a pre-exiting pro-thrombotic abnormality in some women. For example, one of the commonest pro-thrombotic disorders is factor $\mathrm{V}$ Leiden deficiency, occurring in $2-6 \%$ of the general population. This was associated with a 15 fold increased risk of venous thrombosis in a study carried out in Oxford (33) and similar figures were found in the HERS study (6).

Arterial and venous thromboembolism is also increased with the oral contraceptive pill (OCP). An increased risk of ischaemic stroke and MI was first reported soon after the introduction of the OCP in 1962 (34) and 1963 (35). More recent studies have confirmed this increased relative risk with the World Health Organization collaborative study (36) finding a five-fold increase in the risk of $\mathrm{MI}$ and a three-fold increased risk of ischaemic stroke in OCP users. The RATIO study (37) found a two-fold increase in the risk of MI. However, the risk was substantially increased by the presence of additional risk factors (six-fold for hypertensive OCP users, 13.6-fold for smoking OCP users and 17.4-fold for diabetic OCP users). Venous thromboembolism has also been shown to be increased with the OCP, between two- and six-fold (38) and as with HRT, this risk is greatly increased in patients with familial thrombophilia, with Factor V Leiden deficiency increasing the risk 20- to 30-fold (39).

The effect of male and female sex hormones in cardiovascular disease would appear to be different. The increased risk of arterial and venous thromboembolism associated with HRT and the OCP, may not occur with testosterone replacement therapy in men, since physiological doses of testosterone do not adversely affect blood coagulation factor expression. This negative finding is important, since recent research has shown that testosterone is beneficial in 
patients with angina (13-17) and chronic heart failure $(40,41)$. The findings of this study suggest that male hormone replacement therapy may provide cardiovascular benefit without adversely affecting blood coagulation.

\section{References}

1 British Heart Foundation statistics database. British Heart Foundation, 2003.

2 Wingard DL, Suarez L \& Barrettconnor E. The Sex Differential in Mortality from All Causes and Ischemic- Heart-Disease. American Journal of Epidemiology 1983117 165-172.

3 Jousilahti P, Vartiainen E, Tuomilehto J \& Puska P. Sex, age, cardiovascular risk factors, and coronary heart disease - A prospective follow-up study of 14786 middle-aged men and women in Finland. Circulation 199999 1165-1172.

4 Grady D, Rubin SM, Petitti DB, Fox CS, Black D, Ettinger B, Ernster VL \& Cummings SR. Hormone-Therapy to Prevent Disease and Prolong Life in Postmenopausal Women. Annals of Internal Medicine $1992 \mathbf{1 1 7} 1016-1037$.

5 Barrett-Connor E \& Grady D. Hormone replacement therapy, heart disease, and other considerations. Annual Review of Public Health 199819 55-72.

6 Hulley S, Grady D, Bush T, Furberg C, Herrington D, Riggs B \& Vittinghoff E. Randomized trial of estrogen plus progestin for secondary revention of coronary heart disease in postmenopausal women. Jama-Journal of the American Medical Association 1998 $280605-613$.

7 Rossouw JE, Anderson GL, Prentice RL, Lacroix a Z, Kooperberg C, Stefanick ML, Jackson RD, Beresford SA, Howard BV, Johnson KC, Kotchen M \& Ockene J. Risks and benefits of estrogen plus progestin in healthy postmenopausal women - Principal results from the Women's Health Initiative randomized controlled trial. JamaJournal of the American Medical Association 2002288 321-333.

8 Grady D, Herrington D, Bittner V, Blumenthal R, Davidson M, Hlatky M, Hsia J, Hulley S, Herd A, Khan S, Newby LK, Waters D, Vittinghoff E \& Wenger N. Cardiovascular disease outcomes during 6.8 years of hormone therapy - Heart and Estrogen/progestin Replacement Study follow-up (HERS II; 8) Jama-Journal of the American Medical Association $2002 \mathbf{2 8 8}$ $49-57$.

9 Vermeulen A \& Kaufman JM. Aging of the Hypothalamopituitary Testicular Axis in Men. Hormone Research 199543 25-28.

$10 \mathrm{Wu}$ FCW. Endocrine aspects of anabolic steroids. Clinical Chemistry 199743 1289-1292.

11 English KM, Steeds R, Jones TH \& Channer KS. Testosterone and coronary heart disease: is there a link? Qjm-Monthly Journal of the Association of Physicians 199790 787-791.

12 English KM, Mandour O, Steeds RP, Diver MJ, Jones TH \& Channer KS. Men with coronary artery disease have lower levels of androgens than men with normal coronary angiograms. European Heart Journal 200021 890-894.

13 English KM, Steeds RP, Jones TH, Diver MJ \& Channer KS. Lowdose transdermal testosterone therapy improves angina threshold in men with chronic stable angina - A randomized, double-blind, placebo-controlled study. Circulation 2000102 1906-1911.

14 Rosano GMC, Leonardo F, Pagnotta P, Pelliccia F, Panina G, Cerquetani E, Della Monica PL, Bonfigli B, Volpe M \& Chierchia SL. Acute anti-ischemic effect of testosterone in men with coronary artery disease. Circulation 199999 1666-1670.

15 Webb CM, Adamson DL, De Zeigler D \& Collins P. Effect of acute testosterone on myocardial ischemia in men with coronary artery disease. American Journal of Cardiology 199983 437-439, A9.

16 Jaffe MD. Effect of testosterone cypionate on postexercise ST segment depression. British Heart Journal 197739 1217-1222.

17 Wu SZ \& Weng XZ. Therapeutic Effects of an Androgenic Preparation on Myocardial Ischemia and Cardiac-Function in 62
Elderly Male Coronary Heart-Disease Patients. Chinese Medical Journal $1993106415-418$.

18 Alexandersen P, Haarbo J, Byrjalsen I, Lawaetz H \& Christiansen C. Natural androgens inhibit male atherosclerosis - A study in castrated, cholesterol-fed rabbits. Circulation Research $1999 \mathbf{8 4}$ $813-819$.

19 Fukui M, Kitagawa Y, Nakamura N, Kadono M, Mogami S, Hirata C, Ichio N, Wada K, Hasegawa G \& Yoshikawa T. Association between serum testosterone concentration and carotid atherosclerosis in men with type 2 diabetes. Diabetes Care 2003 26 1869-1873.

20 Van Den Beld A, Bots ML, Grobbee DE, Janssen JA, Pols HA \& Lamberts S. Endogenous hormones and carotid atherosclerosis in elderly men. American Journal of Epidemiology 2003157 25-31.

21 Hak AE, Witteman JCM, De Jong FH, Geerlings MI, Hofman A \& Pols HAP. Low levels of endogenous androgens increase the risk of atherosclerosis in elderly men: The Rotterdam study. Journal of Clinical Endocrinology and Metabolism $2002873632-3639$.

22 Thogersen AM, Jansson JH, Boman K, Nilsson TK, Weinehall L, Huhtasaari F \& Hallmans G. High plasminogen activator inhibitor and tissue plasminogen activator levels in plasma precede a first acute myocardial infarction in both men and women Evidence for the fibrinolytic system as an independent primary risk factor. Circulation 199898 2241-2247.

23 Bavenholm P, De Faire U, Landou C, Efendic S, Nilsson J, Wiman B \& Hamsten A. Progression of coronary artery disease in young male post-infarction patients is linked to disturbances of carbohydrate and lipoprotein metabolism and to impaired fibrinolytic function. European Heart Journal 199819 402-410.

24 Tremblay RR \& Dube JY. Plasma concentrations of free and non Te-BG bound testosterone in women on oral contraceptives. Contraception 197410 599-605.

25 Maresca G, Di Blasio A, Marchioli R \& Di Minno G. Measuring plasma fibrinogen to predict stroke and myocardial infarction An update. Arteriosclerosis Thrombosis and Vascular Biology 1999 $191368-1377$.

26 English KM, Steeds RP, Jones TH, Diver MJ \& Channer KS. Low dose transdermal testosterone therapy improves angina threshold in men with chronic stable angina. A randomized, double-blind placebo-controlled stuhdy. Circulation 2000102 1906-1911.

27 Arver S, Dobs AS, Meikle AW, Caramelli KE, Rajaram L, Sanders SW \& Mazer NA. Long-term efficacy and safety of a permeation-enhanced testosterone transdermal system in hypogonadal men. Clinical Endocrinology 199747 727-737.

28 Phillips GB, Pinkernell BH \& Jing TY. The Association of Hypotestosteronemia with Coronary-Artery Disease in Men. Arteriosclerosis and Thrombosis $1994 \mathbf{1 4} 701-706$.

29 Glueck CJ, Glueck HI, Stroop D, Speirs J, Hamer T \& Tracy T. Endogenous Testosterone, Fibrinolysis, and Coronary Heart Disease Risk in Hyperlipidemic Men. Journal of Laboratory and Clinical Medicine 1993122 412-420.

30 Pugh PJ, Channer KS, Parry H, Downes T \& Jones TH. Bio-available testosterone levels fall acutely following myocardial infarction in men: Association with fibrinolytic factors. Endocrine Research 200228 161-173.

31 Anderson RA, Ludlam CA \& Wu FCW. Hemostatic Effects of Supraphysiological Levels of Testosterone in Normal Men. Thrombosis and Haemostasis $1995 \mathbf{7 4} 693-697$.

32 Cherry N, Gilmour K, Hannaford P, Heagerty A, Khan MA, Kitchener H, Mcnamee R, Elstein M, Kay C, Seif M \& Buckley H. Oestrogen therapy for prevention of reinfarction in postmenopausal women: a randomised placebo controlled trial. Lancet 2002 $3602001-2008$.

33 Lowe G, Woodward M, Vessey M, Rumley A, Gough P \& Daly E. Thrombotic variables and risk of idiopathic venous thromboembolism in women aged 45-64 years- Relationships to hormone replacement therapy. Thrombosis and Haemostasis $2000 \mathbf{8 3}$ $530-535$. 
34 Lorentz I. Parietal lesions and Enavid. British Medical Journal 1962 ii 1191.

35 Boyce J, Fawcett JW \& Noall EWP. Coronary thrombosis and Conovid. Lancet 19631111.

36 Poulter NR, Chang CL, Farley TMM, Kelaghan J, Meirlk O, Marmot MG, Debertribeiro M, Medina E, Artigas J, He S, Zhong YH, Zhang DW, Zhao WJ, Rojas O, Heinemann L, Donnan S, Ho S, Bartfai G, Kisjanto J, Wilks R, Agwanda R, Ruiz R, Kozuhnovak M, Dusitsin N, Virutamasen P Phanthumchinda K, Koetsawang S, Piyaanant M, Vessey M, Demirovic J, Belkic K, Mwandila WS, Mutale CM, Matenga J, Wilson A, Vessey MP, Petitti D, Perlman J, Holck S, Lawley S, Smith S, Shipley M, Olsen J \& Thorogood M. Acute myocardial infarction and combined oral contraceptives: Results of an international multicentre case-control study. Lancet $1997 \mathbf{3 4 9}$ $1202-1209$

37 Tanis BC, Van Den Bosch M, Kemmeren JM, Cats VM, Helmerhorst FM, Algra A, Van Der Graaf Y \& Rosendaal FR. Oral contraceptives and the risk of myocardial infarction. New England Journal of Medicine 2001345 1787-1793.

38 Poulter NR, Chang CL, Farley TMM, Meirik O, Marmot MG, Debertribeiro M, Medina E, Artigas J, He S, Zhong YH, Zhang DW, Zhao WJ, Rojas O, Vessey MP, Heinemann L,
Donnan S, Ho S, Bartfai G, Kisjanto J, Wilks R, Agwanda R, Ruiz R, Kozuhnovak M, Dusitsin N, Virutamasen P, Phanthumchinda K, Koetsawang S, Piyaanant M, Demirovic J, Belkic K, Mwandila WS, Mutale CM, Matenga J, Wilson A, Petitti D, Holck S, Lawley S, Smith S, Shipley M, Olsen J, Thorogood M \& Kelaghan J. Venous Thromboembolic Disease and Combined Oral-Contraceptives - Results of International Multicenter Case-Control Study. Lancet 1995346 1575-1582.

39 Vandenbroucke JP, Koster T, Briet E, Reitsma PH, Bertina RM \& Rosendaal FR. Increased Risk of Venous Thrombosis in Oral-Contraceptive Users Who Are Carriers of Factor-V Leiden Mutation. Lancet 1994344 1453-1457.

40 Pugh PJ, Jones TH \& Channer KS. Acute haemodynamic effects of testosterone in men with chronic heart failure. European Heart Journal 200324 909-915.

41 Pugh PJ, Jones RD, West JN, Jones TH \& Channer KS. Testosterone treatment for men with chronic heart failure. Heart 200490 $446-447$.

Received 3 August 2004

Accepted 12 November 2004 